Article

\title{
Risk Factors for Zoonotic Tuberculosis at the Wildlife-Livestock-Human Interface in South Africa
}

\author{
Petronillah R. Sichewo ${ }^{1,2, *}$, Anita L. Michel 1,3 ${ }^{(D)}$, Jolly Musoke ${ }^{4,5}$ and Eric M.C. Etter ${ }^{6,7,8}$ (D) \\ 1 Department of Veterinary Tropical Diseases, Bovine Tuberculosis and Brucellosis Research Programme, \\ Faculty of Veterinary Sciences, University of Pretoria, Private Bag X04, Onderstepoort 0110, \\ Pretoria, South Africa \\ 2 Department of Animal and Wildlife Sciences, Faculty of Natural Resources Management and Agriculture, \\ Midlands State University, P. Bag 9055, Gweru, Midlands 00263, Zimbabwe \\ 3 Research Associate at the National Zoological Gardens of South Africa, Pretoria 0001, South Africa \\ 4 National Health Laboratory Services, Department of Medical Microbiology, Universitas, \\ Bloemfontein 9301, South Africa \\ 5 Department of Medical Microbiology, Faculty of Health Science, University of the Free State, \\ Bloemfontein 9301, South Africa \\ 6 Department of Production Animal Studies, Faculty of Veterinary Sciences, University of Pretoria, Private Bag \\ X04, Onderstepoort 0110, South Africa \\ 7 CIRAD, UMR Animal, Santé, Territoires, Risque et Ecosystèmes (ASTRE), 34398 Montpellier, France \\ 8 ASTRE, Univ Montpellier, CIRAD, INRA, 34398 Montpellier, France \\ * Correspondence: psichewo@gmail.com; Tel.: +27-774-356-3943
}

Received: 29 May 2019; Accepted: 21 June 2019; Published: 14 July 2019

\begin{abstract}
A cross-sectional study was conducted to investigate the risk factors associated with zoonotic tuberculosis in humans and its transmission to people living at the wildlife-livestock-human interface. A questionnaire was administered to collect information on food consumption habits, food handling practices, and knowledge of zoonotic TB. Sputum samples were also collected from 150 individuals that belonged to households of cattle farmers with or without a bTB infected herd. In addition, 30 milk samples and 99 nasal swabs were randomly collected from cattle in bTB infected herds for isolation of Mycobacterium bovis (M. bovis). The sputum samples were screened for TB using the GeneXpert test and this was followed by mycobacterial culture and speciation using molecular techniques. No M. bovis was isolated from TB positive sputum samples and only one sample was confirmed as Mycobacterium tuberculosis (M. tuberculosis). M. bovis was isolated from $6.6 \%(\mathrm{n}=2 / 30)$ milk samples and $9 \%(n=9 / 99)$ of nasal swabs. Ownership of a bTB infected herd and consumption of milk were recognized as highly significant risk factors associated with a history of TB in the household using multiple correspondence analysis (MCA) and logistic regression. The findings from this study have confirmed the potential for zoonotic TB transmission via both unpasteurized milk and aerosol thus, the role of M. bovis in human TB remains a concern for vulnerable communities.
\end{abstract}

Keywords: bovine tuberculosis (bTB); multiple correspondence analysis (MCA); Mycobacterium bovis (M. bovis); risk factors; wildlife-livestock-human interface; zoonotic TB

\section{Introduction}

Cattle are the maintenance host of Mycobacterium bovis (M. bovis) but many other domestic and wildlife animals can be affected by the pathogen [1]. M. bovis belongs to the Mycobacterium tuberculosis complex (MTC), a group of closely related organisms that causes TB in mammals including humans [2]. Although M. tuberculosis is the most common cause of human TB cases, an unspecified fraction occurs due to M. bovis infection and is referred to as zoonotic TB [3-5]. 
The true impact of $M$. bovis on the human TB epidemic is unclear due to the lack of routine bovine TB surveillance data from humans and resources for the identification of M. bovis [6,7]. In 2016 it was estimated that 147,000 new cases of zoonotic TB were reported in people, and 12,500 deaths due to the disease globally and most of these occurred in Africa [8]. Using the data that was available at the time of the study, Müller et al. (2013) estimated that M. bovis might be responsible for up to $37.7 \%$ of all human TB cases in Africa [6]. In studies carried out in several African countries M. bovis has been isolated from lymph node biopsies or aspirates of TB patients, in Uganda at a prevalence of 7\%, in Tanzania 16\% and in Ethiopia 17\% [9-11]. While recent investigations in Zambia and Uganda diagnosed $M$. bovis at a prevalence of $<1 \%$ and $<3 \%$, respectively from sputum samples of pulmonary TB patients [12,13].

Zoonotic TB is primarily acquired through the consumption of unpasteurized milk and dairy products, less frequently from eating of raw or improperly cooked infected meat and via aerosols inhaled from infected animals during direct human-livestock contact [5,14]. This supports the observation that zoonotic TB occurs more frequently as extra-pulmonary TB (EPTB) $(9.4 \%)$ in humans than in the pulmonary form (2.1\%) as mentioned by Etter et. al., (2006) [15]. The 'test and slaughter policy', compulsory pasteurization of milk and abattoir surveillance have been successfully implemented in developed countries leading to the near elimination of the disease in cattle and human populations [6]. Unlike in developing countries, particularly in Africa, these policies are absent or inadequate due to lack of resources, thus bTB is widespread in animals [16].

Risk factors for M. bovis transmission to people include demographic factors (e.g., number of family members, age), feeding habits, people living in close contact with their animals, socio-economic status, illiteracy (lack of knowledge of zoonotic TB), customs, traditions coupled with the increasing prevalence of HIV/AIDS pandemic $[5,14,16,17]$. Nevertheless, the principal risk factors that govern bTB epidemiology and transmission to humans living at the wildlife-livestock-human interface remain largely unknown in sub-Saharan Africa including South Africa.

In northern KwaZulu-Natal, in addition of bTB being endemic in wildlife in the game reserves such as the Hluhluwe iMfolozi, the disease was previously detected in cattle in the surrounding communal area with an overall herd prevalence of $28 \%[18,19]$. The community is in this province with one of the highest TB incidence rate of $685 / 100,000$ ) and an HIV prevalence of $27 \%$ in the country, where consumption of unboiled milk is a common practice, indicative of a significant role of M. bovis in human TB [20-22]. In addition, there is a presumptive lack of knowledge among livestock farmers on zoonotic TB and protective practices against zoonotic TB transmission have never been examined in the area. Against this background, there was a need to investigate the possible risk factors for bovine tuberculosis transmission from cattle to humans in a One Health approach and to assess the farmers' knowledge of zoonotic TB. The findings from this study will assist the policy makers in the selection of appropriate preventive animal health measures and designing of awareness programs led by community health workers.

\section{Results}

\subsection{Household Study}

Sputum and serum samples were collected from 75 individuals from households that owned bTB test positive cattle, similarly 75 samples were collected from households that owned bTB test negative cattle. This was less than the expected sample size of 300 and we attribute the low numbers to the absence of some family members during the times we visited their homesteads, and the unwillingness of either individuals or guardians (for children below the age of 15) to participate. Most of the individuals that participated were mostly men 62\% (94/150) aged between 16-64 years as shown in Table 1. According to the cultural practices in the area, it is mostly the men that are involved in livestock activities. 
Table 1. Mycobacterium tuberculosis complex and HIV status of household members based on bTB herd status.

\begin{tabular}{cccccc}
\hline $\begin{array}{c}\text { bTB Herd } \\
\text { Status }\end{array}$ & Age Group & $\begin{array}{c}\text { No. of } \\
\text { Participants }\end{array}$ & $\begin{array}{c}\text { TB Positive } \\
\text { (GeneXpert) }\end{array}$ & $\begin{array}{c}\text { Confirmed } \\
\text { M.tuberculosis }\end{array}$ & $\begin{array}{c}\text { HIV } \\
\text { Prevalence }\end{array}$ \\
\hline bTB positive & 16-64 years & 68 & 5 & 1 & $40 \%(30 / 75)$ \\
herd & $>64$ years & 7 & 2 & - & - \\
bTB negative & 16-64 years & 72 & 3 & - & $33 \%(25 / 75)$ \\
herd & $>64$ years & 3 & - & - & - \\
\hline
\end{tabular}

M. bovis was not isolated from individuals in the study population. Out of the 10 samples that were TB positive from the GeneXpert test none of the samples were identified as M. bovis; only one sample was confirmed as M. tuberculosis through culture and deletion analysis of the RD4 and the rest of the samples were negative for mycobacterial organisms as shown in Table 1 . The estimated population prevalence of $M$. bovis was $1.33 \%$ confidence interval (C.I) [0;3.92] and $<3.92 \%$ respectively for participants from households that owned bTB positive and uninfected herds. The GeneXpert test is the standard TB diagnostic in South Africa as recommended by the World Health Organisation for diagnosis of pulmonary TB [23]. The Gene Xpert (Cepheid), identifies Mycobacterium tuberculosis complex organism and determines drug resistance to rifampicin in TB positive samples. The overall HIV prevalence was $36 \%$ (individuals aged between 16-64) and there was no significant difference in HIV infection between the farmers that owned bTB infected and uninfected herds (Chi-squared test: $p$ value $=0.5$ ). Results in Table 1 summarizes the TB and HIV results from the household study. The participants that were unaware of their TB status $(6 \%)$ or HIV status $(10 \%)$ prior to enrolling in this study were informed of their results by the Department of Health at their respective clinics and received appropriate treatment.

\subsection{Bovine Samples}

A total of 30 milk samples and 99 nasal swabs were collected from bTB infected herds. The milk yield was low, and some lactating animals had ceased milk production due to the drought in the study area at the time of sampling. M. bovis was isolated from $9 \%(\mathrm{n}=9)$ of nasal swabs from infected herds and from $6.6 \%(n=2)$ of the collected milk samples.

\subsection{Questionnaire Survey}

A total of 71 participants took part in the questionnaire survey, comprising $59 \%(n=42)$ from households with bTB infected herds and $41 \%(n=29)$ from households that owned uninfected herds. This is less than the calculated number of farmers (100) and this was due to the unavailability of family members because of work commitments and livestock herding activities. In a few cases there were elderly or young people at home who could not answer questions logically and people not willing to participate in the study.

\subsection{Descriptive Analysis}

Of the 71 participants, $40 \%(n=31)$ reported a history of TB diagnosis in the family and $60 \%$ $(\mathrm{n}=40)$ had no history of TB diagnosis in the family. The household demographics are summarized in Table 2 below.

Most of the participants were involved in the herding (100\%) and milking of cows (86\%). The participants reported consumption of milk $(98 \%)$, especially as sour milk $(89 \%)$ and this involved all the family members in $97 \%$ of the households. Most of the households obtained meat from their own cattle $(94 \%)$ but none involved veterinary services for the inspection of the meat. More than $50 \%$ of the households had observed abnormal spots on organs that looked like TB lesions (as shown on the pictures by the interviewer) at least once during informal slaughtering. The family members of cattle owning households displayed poor knowledge of the disease transmission modes with $56 \%$ 
being unaware of the zoonotic aspect of bovine tuberculosis and $63 \%$ being unable to give examples of protective practices during slaughter of animals. This is summarized in Table 3.

Table 2. Summary of household demographics determined by questionnaire survey.

\begin{tabular}{ccc}
\hline Variable & Level & Response $(\mathbf{n}=\mathbf{7 1}) \mathbf{\%}$ \\
\hline \multirow{2}{*}{ Gender } & Male & 66 \\
& Female & 34 \\
\hline \multirow{2}{*}{ Age group } & $16-64$ years & 87 \\
& $>64$ years & 13 \\
\hline \multirow{3}{*}{ Status in the family } & Cattle owner & 31 \\
& Cattle keeper & 11 \\
& Member of the household & 58 \\
\hline \multirow{2}{*}{ Education } & No Education & 18 \\
& Primary education & 23 \\
& Secondary education & 17 \\
& High school & 34 \\
\hline
\end{tabular}

Table 3. Risk factors and awareness of bTB as determined by questionnaire.

\begin{tabular}{|c|c|c|c|}
\hline Category & Variable & Level & $\begin{array}{l}\text { Responses } \\
(n=71) \%\end{array}$ \\
\hline \multirow{22}{*}{ Food consumption habits } & Do you regularly consume milk & Yes & 98 \\
\hline & from your animals? & No & 2 \\
\hline & \multirow{3}{*}{$\begin{array}{l}\text { Who mainly consumes milk in the } \\
\text { household? }\end{array}$} & Whole household & 97 \\
\hline & & $<12$ & 1.5 \\
\hline & & $>64$ years & 1.5 \\
\hline & \multirow{3}{*}{ How often is milk consumed? } & Daily & 3 \\
\hline & & Weekly & 63 \\
\hline & & When needed & 34 \\
\hline & \multirow{3}{*}{ How do you consume your milk? } & Soured (Amasi) & 89 \\
\hline & & Raw & 6 \\
\hline & & Boiled & 4 \\
\hline & \multirow{3}{*}{ What is your source of meat? } & Supermarket & 58 \\
\hline & & Own cattle & 94 \\
\hline & & Buy from others & 17 \\
\hline & \multirow{4}{*}{$\begin{array}{c}\text { How do you process meat with } \\
\text { abnormal spots? }\end{array}$} & Never seen spots & 48 \\
\hline & & Throw away meat & 25 \\
\hline & & Overcook meat & 13 \\
\hline & & Normal use of meat & 11 \\
\hline & \multirow{4}{*}{ What is your source of water? } & Boiling & 3 \\
\hline & & Own well & 27 \\
\hline & & Borehole & 59 \\
\hline & & Communal & 14 \\
\hline
\end{tabular}

\subsection{Risk Factor Analysis}

The analysis of risk factors was done using the history of TB in the family as reference variable (MCA) or the fixed (outcome) variable (Fisher test and general linear model).

\subsubsection{Univariate Analysis and Logistic Regression of Risk Factors for bTB Transmission to Humans}

Out of the 20 variables that were analysed using univariate analysis, five significant factors were identified ( $p$ value $<0.25$ ) namely: consumption of milk weekly and when needed, consumption of meat from own cattle or from other farmers and ownership of a bTB positive herd as shown in Table 4 . 
Table 4. Univariate analysis of bTB transmission to people in cattle owning households.

\begin{tabular}{ccc}
\hline Factor & $p$ Value & Odds Ratio (95\% CI) \\
\hline Weekly consumption of milk & 0.31 & $0.24(0.04-3.22)$ \\
Consumption of milk when needed & 0.20 & $2.14(0.70-6.74)$ \\
Purchase of meat from other farmers & 0.21 & $0.37(0.06-1.70)$ \\
bTB positive herd & $<0.01$ & $10.8(2.97-51.08)$ \\
\hline
\end{tabular}

\subsubsection{Multiple Correspondence Analysis}

The risk factors/practices that were closely related to the history of TB diagnosis in a family are: ownership of a bTB positive herd, not purchasing meat from other farmers, ownership of herds that belonged to Mpempe dip tank and farmers that had never seen abnormalities or TB like lesions on cattle organs during slaughter. Absence of history of TB diagnosis in the family was closely related to the ownership of an uninfected herd and previous observation of abnormalities or TB like lesions on organs from their animals. This is illustrated in Figure 1 depicting the history of TB diagnosis (positive) and related risk factors/practices inside the red circle and absence of history of TB diagnosis (negative) in the family and related protective factors/practices inside the blue circle.

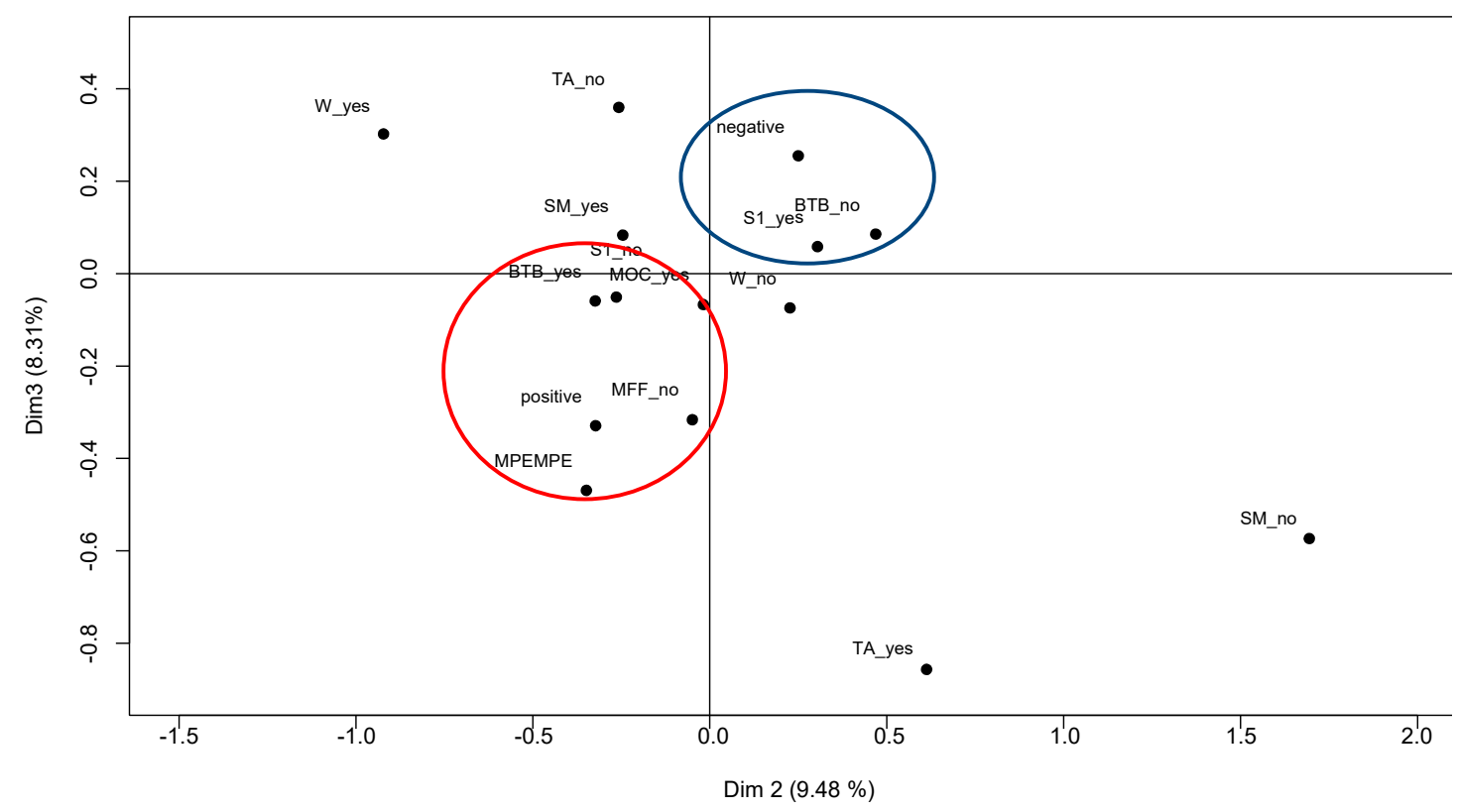

\section{KEY}

BTB: bTB positive /negative herd MFF: meat from other farmers S1: spots/TB like lesions $\mathrm{W}$ : weekly consumption of milk Mpempe: Mpempe dip tank
MOC: meat from own cattle SM: sour milk; TA: awareness of TB transmission Positive: history of TB in the family Negative: no history of TB in the family

Figure 1. Multiple correspondence analysis of risk factors associated with history of TB diagnosis in the family (positive or negative).

\subsubsection{Logistic Regression of Risk Factors for bTB Transmission to Humans}

All the statistically significant factors from the univariate analysis $(p<0.3)$ and other risk factors of biologically importance were included in the logistic regression model; the significant risk factors identified were, ownership of a bTB positive herd and consumption of milk from own cattle while consumption of meat from own cattle or other farmers were identified as protective practices as presented in Table 5. 
Table 5. Significant risk factors for bTB transmission to people that live in the households that own cattle from logistic regression.

\begin{tabular}{lccl}
\hline \multicolumn{1}{c}{ Factor } & $p$ Value & Adjusted OR & \multicolumn{1}{c}{ CI $_{\mathbf{9 5 \%}}$} \\
\hline Bovine TB positive cattle & $0.00009^{* * *}$ & 29.308 & $6.495-208.361$ \\
Consumption of milk when needed & $0.0393^{*}$ & 4.937 & $1.197-27.130$ \\
Consumption of meat from own cattle & $0.0493^{*}$ & 0.053 & $0.001-0.755$ \\
Consumption of beef bought from other farmers & 0.0674 & 0.105 & $0.005-0.866$ \\
Awareness of bTB transmission & $0.0471^{*}$ & 4.419 & $1.101-22.067$ \\
\hline
\end{tabular}

Notes: ${ }^{*} p<0.05^{* * *} p<0.001$.

\section{Discussion}

The aim of this study was to investigate $M$. bovis infection in humans exposed to bTB infected cattle and the risk factors associated with zoonotic TB in a community living at the wildlife-livestock-human interface. M. bovis excretion was confirmed in milk (6.6\%) and nasal discharges (9\%) and the associated risk factors identified included consumption of unpasteurized milk particularly as sour milk and ownership of bTB infected cattle. The actual excretion rate in milk and nasal discharges should, however, be deemed higher due to loss of viable organisms during sample processing, the intermittent shedding of the pathogen by infected animals and the sensitivity of the culture method [24,25].

Despite the community's apparent exposure risk, $M$. bovis was not detected in sputum samples collected from individuals that belonged to households that owned cattle. This raises the question whether M. bovis is not transmitted in high enough numbers to infect humans or whether the loss of live organisms was too severe and reduced the viable bacterial concentration below the limit of detection, or alternatively whether the threshold of infection in cattle was too low to cause disease in humans. The latter is because bTB prevalence in the cattle populations under study was reported as $12 \%$ while the bTB prevalence in cattle in Britain, which was $40 \%$ in the 1940 s, was linked to a $6 \%$ M. bovis infection burden in human TB $[18,26,27]$. Similar results have also been reported in Ethiopia at a wildlife-livestock-human interface with low bTB prevalence rate in cattle [28]. Another possible explanation for the absence of $M$. bovis infection in humans might be due to life-long protection against $M$. bovis as induced by Bacillus Calmette-Guerin (BCG) vaccination at birth. However, further evaluations have revealed that BCG's protective efficacy against $M$. tuberculosis infection and progression to disease is not absolute [29]. It has also been proposed that humans are more resistant to $M$. bovis as compared to $M$. tuberculosis as explained by reduced transmissibility and a lower risk of human disease establishment after infection $[27,30]$.

Considering consumption of milk was identified as a significant risk factor and the apparent excretion of M. bovis in milk by lactating animals, non-pulmonary TB is highly likely to affect the exposed individuals. Therefore, sputum might have been an unsuitable sample for the detection of $M$. bovis in people that might be affected by non-pulmonary forms of TB as discussed by Debi et al. 2014 [31]. On the other hand, the participants had no apparent TB clinical signs such as a productive chronic cough, thus they experienced it challenging to produce sputum and instead inappropriate samples of saliva were collected which could have reduced the chance of detecting an underlying M. bovis infection. This was also supported by the discrepancy in the GeneXpert and culture results whereby, 10 sputum samples were GeneXpert positive and yet only one sample was positive for $M$. tuberculosis using culture. The GeneXpert test is a PCR based test that depends on the pathogen's DNA in saliva hence displays a higher sensitivity and specificity than culture [32], whereas, culture results are affected by the number and viability of bacteria and quality of the sputum processed [33] which was influenced by the distance and transport delays between collection and processing of sputum as the study was in a remote area.

In corroboration with our results, a study carried out in the Serengeti ecosystem of Tanzania did not find M. bovis from the sputa of TB patients despite the presence of the infection in cattle and wildlife [34]. Similarly, studies in Brazil, Uganda and Cote d'Ivoire found no M. bovis from 
human samples that included sputa despite bTB being prevalent in the cattle populations of these countries $[12,35,36]$. In contrast, $M$. bovis has been detected in sputum samples of livestock traders in Nigeria (10\%) and pastoral communities in Ethiopia (15\%) from both sputum and fine needle aspirates specimens $[37,38]$. The high prevalence in Ethiopia could be explained by cattle farmers sharing shelter with their livestock while in this study, none of the farmers shared living space with animals $[17,38]$. Findings from these individual studies indicate that zoonotic TB is a disease of public health importance particularly in poor-resourced communities that should not be ignored [6].

In this study, consumption of milk and meat from own cattle were identified as highly significant risk factors for TB in people. Moreover, most of the households $(89 \%)$ reported consumption of milk as sour milk by almost everyone in the households (97\%), predisposing the individuals to $M$. bovis infection. Consumption of soured milk frequently (weekly), as indicated by two thirds of the respondents may increase the risk of repeated $M$. bovis exposure for a higher number of consumers. It has been demonstrated that $M$. bovis persists for up to 14 days in soured milk depending on the initial bacterial concentration in raw milk, souring and storage temperature. This is further exacerbated by the commonly practiced pooling and supplementation of milk with left over sour milk "stock" for a continuous production of sour milk that results in the contamination of milk from uninfected animals [39]. The results suggest ingestion of contaminated food as the most important route of infection and this would primarily result in extra-pulmonary TB, making it highly unlikely to detect M. bovis infection in sputa. M. bovis infection is frequently associated with extra-pulmonary as demonstrated by studies in Tanzania and Ethiopia where M. bovis was more prevalent in cases of extra-pulmonary TB than pulmonary TB $[10,38]$. However, in the present study cases of lymphadenitis (EPTB) were not encountered. The initial $M$. bovis load from the lactating cows might be too low to survive souring hence absence of EPTB in people as supported by the absence of the bacteria from the culture of milk samples that were collected sporadically from the infected cows in the study area over a period of 12 months [40].

All the farmers reported absence of meat inspection by veterinary public health officers during slaughter and $48 \%$ had no knowledge of the TB lesions that characterised organs of an infected animal. Inspection of meat at slaughter is of significance to control the spread of M. bovis infection from infected cattle to humans through removal of contaminated organs or condemnation of carcasses with disseminated bTB. It also facilitates the trace-back of $M$. bovis infection to herd level in eradication programs such as the one that was implemented in European countries in the 1960s to control zoonotic TB in humans [27]. Consumption of meat from the supermarket that undergoes regular inspection at the abattoirs was reported by more than half of the families (58\%). In addition, consumption of meat from own cattle or bought from other farmers were indicated as protective practices. The consumption of undercooked contaminated meat has been previously reported in other investigations as a potential risk factor for transmission of Mycobacteria and other zoonotic diseases to humans although the public health significance is yet to be quantified $[5,14,41-43]$.

The households that owned uninfected herds were associated with the absence of previous diagnosis of human TB but also with reporting of previous observations of organ abnormalities in slaughter animals. Equipped with this knowledge these households may be less likely to consume infected meat and thus be better protected against food borne zoonoses. These findings support the assumption that knowledge of bTB in cattle and its control is linked to a reduced risk to zoonotic TB.

Previous studies have reported ownership of cattle, direct contact with animals and living in close proximity with animals as important drivers of zoonotic TB transmission to people [43-45]. In this study, livestock keeping activities were not identified as risk factors although all the respondents participated in at least one livestock keeping activity such as milking, herding or examination of animals, none of them slept with or near their animals. We conclude that transmission of M. bovis through direct contact was less likely to occur in our study area due to the short periods of exposure of individuals in a confined environment to infected herds. In contrast, the livestock traders of Nigeria 
trade in a congested environment for long periods of time with increased human-to-cattle contact leading to zoonotic TB [37].

Approximately two thirds of the respondents were not aware of zoonotic TB transmission from cattle to humans. The lack of understanding of disease transmission precludes protective practices that contribute to effective disease control programs. In contrast with other studies elsewhere which demonstrated a positive correlation of zoonotic TB knowledge with post primary education this was apparently not the case in our study where $59 \%$ of the participants had post primary education $[43,46]$.

\section{Materials and Methods}

\subsection{Study Area}

The study was conducted from August to September 2017, in four villages from Big 5 False Bay Municipality in uMkhanyakude district, northern Kwa-Zulu Natal province, South Africa. The municipality is situated between game reserves that include iSimangaliso Wetland Park (formerly St. Lucia) and Hluhluwe iMfolozi Park (HiP). Most of the land in the municipality is used for subsistence farming, game lodge activities and the north-eastern parts of the municipality are occupied by densely settled rural traditional communities. The study involved the cattle owners from four villages (Mnqobokasi, Makhasa, Mduku and Nibela), that were associated with the four dip tanks respectively (Masakeni, Mpempe, Nkomo, Nibela) where bTB testing of cattle had been carried out as part of a research project in 2016 and 2017 [18].

\subsection{Study Population}

The study population was recruited from the households that owned cattle herds that belonged to one of the 4 dip tanks. Participation in the study was voluntary, participants were approached through the community health care givers and the purpose of the study was explained. The case-control study involved two groups of households; 50 households that owned bTB infected herds and an equal number of cattle farmers that owned uninfected herds. Three family members were recruited from each household representing the three age categories: adolescents below 15 years, adults 16-64 years and the elderly above 64 years. The total number of participants calculated was 300, comprising of individuals that included head of households (cattle owners), herd boys/man/women (cattle keepers) and female family members of the cattle owning households.

\subsection{Household Study}

At household level samples (sputum and serum) were collected from three members of the family and a questionnaire was administered to one member of the household, either the cattle owner or cattle keeper or female household member.

\subsubsection{Collection and Processing of Human Samples}

The research team visited each of the selected households and collected two sputum samples of approximately 2-5 mL into sterile, leak proof plastic container and 3-6 $\mathrm{mL}$ of blood into serum separating tubes (SST) from each participant. The name, age and gender for each participant was recorded but for the purpose of the study and confidentiality a unique code was allocated to each participant and served as an identifier on the sample containers. The samples were transported to the local district hospital (Mseleni NHLS laboratory) in a cold chain at $4{ }^{\circ} \mathrm{C}$ for the GeneXpert test.

The GeneXpert test is the standard TB diagnostic in South Africa as recommended by the World Health Organisation for diagnosis of pulmonary TB [23]. The Gene Xpert (Cepheid), identifies Mycobacterium tuberculosis complex organism (does not differentiate M. bovis and M. tuberculosis) and determines drug resistance to rifampicin in TB positive samples. The 2nd sputum samples from all the TB positive samples were transported in equal volumes of cetylpyridinium chloride (CPC) $(1 \%)$ in a cold chain for mycobacterial culture and M. bovis identification at the National 
Health Laboratory Services (NHLS) Medical Microbiology University of the Free State. The serum samples were transported to Inkosi Albert Luthuli hospital-NHLS laboratory for HIV testing using the Enzyme-linked immunosorbent assay (ELISA) serological test. The sample collection and processing procedure is shown in Figure 2.

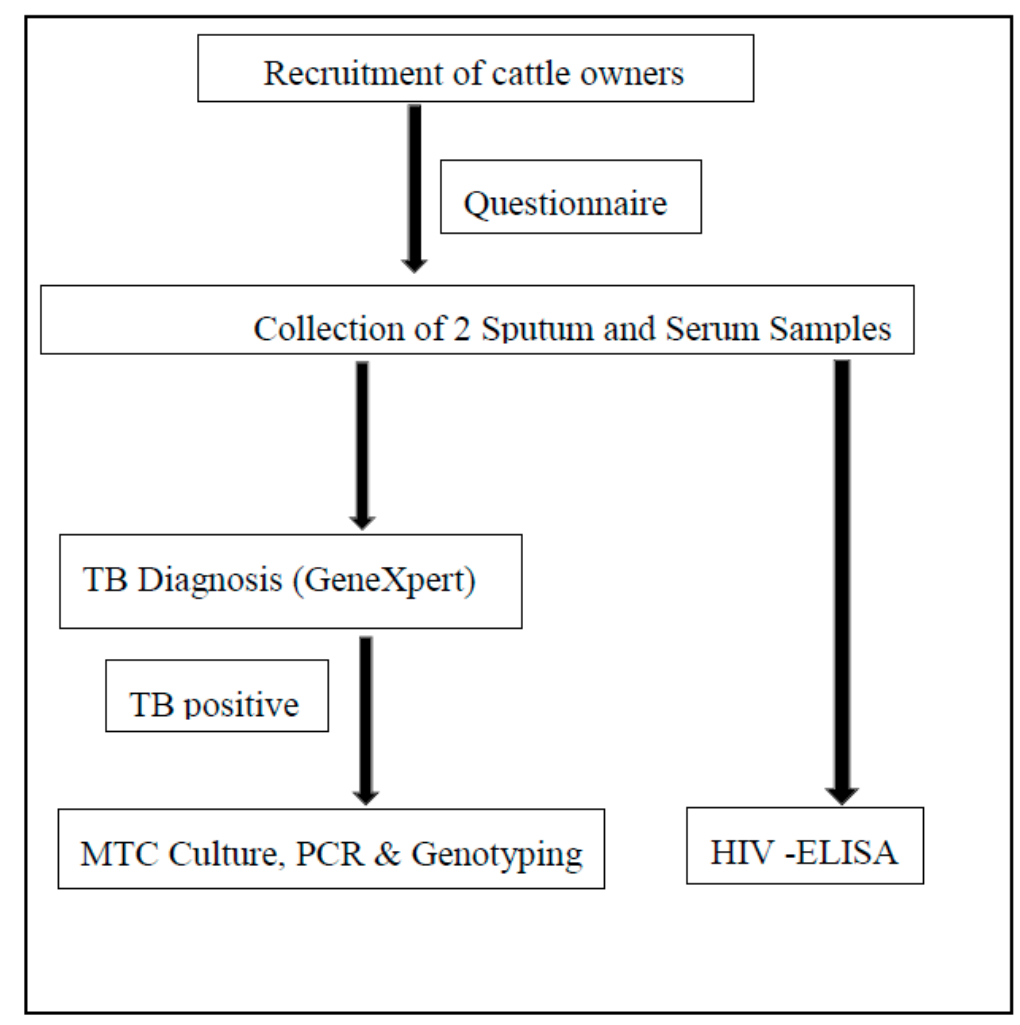

Figure 2. A flow chart of sample collection from households of cattle farmers (including cattle owners and cattle keepers) and laboratory processing for human samples (sputum and serum) and questionnaire administration.

\subsubsection{Mycobacterium Species Culture and Identification}

Sputum samples from participants found to be positive for TB during the screening test were inoculated into Mycobacterial growth indicator tube (MGIT) broth, incubated at $37^{\circ} \mathrm{C}$ in a BD Bactec MGIT 320 with daily monitoring for 28 days and then once a week for up to 42 days. MGIT broth supports the growth of both M. bovis and M. tuberculosis. DNA was extracted from growth positive cultures using the Hain Genolyse kit reagents according to the manufacturer's instructions. Briefly, $1 \mathrm{~mL}$ of the MGIT culture was centrifuged at $1000 \mathrm{~g}$ for $15 \mathrm{~min}$, the pellet resuspended in $100 \mathrm{uL}$ of lysis buffer followed by incubation for $5 \mathrm{~min}$ at $95^{\circ} \mathrm{C}$. For neutralisation, $100 \mathrm{uL}$ of the buffer was added, centrifuged for 5 min at maximum speed and the supernatant stored as DNA for subsequent reactions. The DNA was used as a template in deletion analysis using PCR reaction for confirmation of mycobacterial growth as $M$. bovis targeting the region of difference (RD), RD4 as previously outlined by Warren et al. (2006) [47].

\subsubsection{Questionnaire Survey}

A pre-tested questionnaire with open-ended and closed questions was administered for 20-30 min (face-to-face interviews) to one household member above 18 years that was involved with livestock keeping activities. The questionnaire was developed in English and was translated into the local language of isi-Zulu. The questionnaire was divided into four sections. The first section detailed demographic characteristics, and this included age, sex, level of education and number of family 
members. The second section prompted the interviewee to respond to questions pertaining to livestock management activities such as frequency of human-to-cattle contact during activities such as herding, milking and examination of the animals. The third section invited the respondents to answer questions on their food consumption behavior, food handling and processing practices. The questions in the fourth section were on the knowledge and awareness of bovine tuberculosis in cattle, humans and the history of TB in the family for the past 12 months.

\subsection{Collection of Cattle Samples}

Nasal swabs and milk samples were collected from cattle from bTB infected herds as previously determined by the interferon gamma assay (IFN- $\gamma$ ) $\left(\right.$ BOVIGAM $\left.^{\circledR}\right)$ [18]. Households with bTB positive herds brought their animals to the dip tank, milk was systematically collected from lactating animals and nasal swabs through random sampling of the animals. From a herd with $>10$ animals, every 5 th animal was sampled while for herds $<10$ every 3 rd animal was sampled.

\subsubsection{Collection and Processing of Milk Samples}

Verbal consent was obtained from the cattle owners before milking commenced. We intended to collect $50 \mathrm{~mL}$ of milk per animal, but the actual quantities collected depended on the availability of milk from the lactating animals. The milking was done manually, and $20-40 \mathrm{~mL}$ of milk was collected into sterile screw-capped $50 \mathrm{~mL}$ sterile centrifuge tubes by the cattle owner or cattle keeper after rinsing their hands and udder with $70 \%$ alcohol. The tubes were labelled with a unique code that identified the herd and placed in a cool box for transportation to the local state veterinary laboratories where it was stored at $-20^{\circ} \mathrm{C}$ until processing at University of Pretoria-Department of Veterinary Tropical Diseases BSL 2+ laboratory.

Milk decontamination was done using cetylpyridinium chloride (CPC) as previously described by Michel et al. [39]. The sediments were inoculated onto Löwenstein Jensen slopes supplemented with pyruvate and antibiotics cocktail (polymyxin B (200 IU/ml), amphotericin B $(10 \mu \mathrm{g} / \mathrm{mL})$ carbenicillin $(100 \mu \mathrm{g} / \mathrm{mL})$ and trimethoprim $(10 \mu \mathrm{g} / \mathrm{mL}))$ and incubated at $37^{\circ} \mathrm{C}$ for 10 weeks with weekly monitoring for bacterial growth.

\subsubsection{Collection and Processing of Nasal Swabs}

Nasal swabs were collected from bTB infected cattle using a 50-cm long homemade sterile swab made of aluminum wire and gauze from one nasal passage per animal. These were immediately immersed and expunged into $25 \mathrm{~mL}$ of sterile phosphate buffer saline (PBS) at $\mathrm{pH}=7$ in $50 \mathrm{~mL}$ centrifuge tubes in the field. The samples were kept at $4{ }^{\circ} \mathrm{C}$ until they were processed for $\mathrm{M}$. bovis isolation and identification. The decontamination of nasal swabs was performed using $2 \% \mathrm{HCl}$ as described by Gcebe et al. [48]. The sediments obtained after decontamination were incubated for 20 hours after adding $1 \mathrm{~mL}$ of $50 \mu \mathrm{g} / \mathrm{mL}$ of amphotericin B (antifungal). The solution was then inoculated onto Löwenstein Jensen media with pyruvate and a cocktail of antibiotics (polymyxin B (200 IU/ml), amphotericin B $(10 \mu \mathrm{g} / \mathrm{mL})$ carbenicillin $(100 \mu \mathrm{g} / \mathrm{mL})$ and trimethoprim $(10 \mu \mathrm{g} / \mathrm{mL})$ (NHLS, South Africa)) and incubated at $37^{\circ} \mathrm{C}$ for 10 weeks.

\subsubsection{Mycobacterium Bovis Identification}

Crude DNA extraction from M. bovis isolates was done by boiling a loopful of cells in $100 \mu \mathrm{L}$ of distilled water using a heating block for $25 \mathrm{~min}$ at $95^{\circ} \mathrm{C}$ [49]. M. bovis was confirmed in the isolates using deletion analysis as described by Warren et al., targeting RD4 and RD9 primers recognized by the amplification of DNA products with band sizes $268 \mathrm{bp}$ and $108 \mathrm{bp}$, respectively [47]. 


\subsection{Statistical Analysis}

All the data collected during the household study, questionnaire survey, bovine and milk samples results were stored in Microsoft Excel. The data from the questionnaire survey were exported and analysed with the R software (C) 3.4.4, 2018, R Foundation for Statistical Computing, Vienna, Austria). Bovine TB transmission from cattle to humans was initially examined using general descriptive analysis. The effect of potential risk factors on the variable history of TB diagnosis in members of cattle owning households was analysed using the univariate analysis by means of the two-tailed Fischer's exact test. The association of explanatory variables with a history of TB patients in the households was further described using the multiple correspondence analysis (MCA) [50]. The effect of potential risk factors on TB in people was analysed using univariate analysis using the two-tailed Fischer's exact test. Logistic regression analysis was performed to quantify these risk factors (Generalised Linear model $($ GLM-family $=$ binomial $)$ using the significant risk factors from the univariate analysis $(p<0.25)$.

\subsection{Ethical Clearance}

Animal ethical and biosafety transport clearances were obtained from the University of Pretoria Animal Ethics committee (Ref: V078-16) and the Department of Agriculture Forestry and Fisheries under Section 20 (12/11/1/1/6/1). Ethical clearance for human study was obtained from the University of Pretoria Ethics committees in the Faculty of Health Sciences (321/2016) for sputum and sera collection and Faculty of Humanities (GWO170814HS) for the questionnaire survey. The study was also explained to the participants before collection of samples and verbal and written consent obtained.

\section{Conclusions}

The isolation of $M$. bovis from milk and nasal secretions confirms that there is a potential risk of bovine tuberculosis transmission from cattle to humans through exposure to respiratory exudates, from aerosols and supported by the consumption of contaminated raw and sour milk. Nevertheless, the current study could not confirm $M$. bovis transmission between animals and humans at the wildlife-livestock-human interface. Therefore, in this population there was no link between food consumption practices and transmission of zoonotic TB to people. However, the presence of $M$. bovis in animal products that are known to be consumed by farmers without specific precaution is of significance in the designing of control and management measures that will reduce the impact of the disease on human health.

Author Contributions: Conceptualization, A.L.M.; E.M.C.E.; Resources supervision, A.L.M.; J.M., P.R.S.; E.M.C.E.; Methodology, A.L.M. and E.M.C.E.; Formal analysis, P.R.S. and E.M.C.E.; Investigation, P.R.S. and J.M.; Writing—original draft preparation, P.R.S.; Writing—review and editing, P.R.S.; J.M.; A.L.M.; E.M.C.E.; Funding acquisition, A.L.M. and J.M.

Funding: This research was funded by The National Research Foundation grant number 113594, The National Research Foundation, Thuthuka grant ref TTK160525166191 and the Institute of Tropical Medicine, Belgium for the funding received through the grant agreement with the Department of Veterinary Tropical Diseases, University of Pretoria.

Acknowledgments: We thank the health authorities from Department of Health-province of Kwa-Zulu Natal, uMkhanyakude district and Mseleni Hospital. The laboratory staff, nurses from the local clinics and community care givers are acknowledged for their kind assistance. We are grateful to the farmers of Big 5 False Bay Municipality, uMkhanyakude district for consenting to participate in our study.

Conflicts of Interest: The authors declare no conflict of interest.

\section{References}

1. Michel, A.L.; Müller, B.; Van Helden, P.D. Mycobacterium bovis at the animal-human interface: A problem, or not? Vet. Microbiol. 2010, 140, 371-381. [CrossRef] [PubMed]

2. Galagan, J.E. Genomic insights into tuberculosis. Nat. Rev. Genet. 2014, 15, 307-320. [CrossRef] [PubMed]

3. WHO. Global Tuberculosis Report; WHO: Geneva, Switzerland, 2018. 
4. Miller, M. Tuberculosis in South African Wildlife: Why Is It Important; Sun Media: Stellenbosch, South Africa, 2015.

5. Gumi, B.; Schelling, E.; Berg, S.; Firdessa, R.; Erenso, G.; Mekonnen, W.; Hailu, E.; Melese, E.; Hussein, J.; Aseffa, A.; et al. Zoonotic Transmission of Tuberculosis Between Pastoralists and Their Livestock in South-East Ethiopia. EcoHealth 2012, 9, 139-149. [CrossRef] [PubMed]

6. Müller, B.; Dürr, S.; Alonso, S.; Hattendorf, J.; Zinsstag, J.; Laisse, C.J.; Parsons, S.D.; Van Helden, P.D. Zoonotic Mycobacterium bovis-induced tuberculosis in humans. Emerg. Infect. Dis. 2013, 19, 899-908. [CrossRef] [PubMed]

7. Olea-Popelka, F.; Muwonge, A.; Perera, A.; Dean, A.S.; Mumford, E.; Erlacher-Vindel, E.; Raviglione, M. Zoonotic tuberculosis in human beings caused by Mycobacterium bovis-A call for action. Lancet Infect. Dis. 2017, 17, e21-e25. [CrossRef]

8. World Health Organization (WHO). Food and Agriculture Organisation of the United Nations (FAO); World Organisation for Animal Health (OIE) IUAT and International Union Against Tuberculosis and Lung Disease (The Union). Road map for zoonotic tuberculosis. In Proceedings of the 48th Union World Conference on Lung Health, Guadalajara, Mexico, 11-14 October 2017.

9. Kidane, D.; Olobo, J.O.; Habte, A.; Negesse, Y.; Aseffa, A.; Abate, G.; Yassin, M.A.; Bereda, K.; Harboe, M. Identification of the Causative Organism of Tuberculous Lymphadenitis in Ethiopia by PCR. J. Clin. Microbiol. 2002, 40, 4230-4234. [CrossRef] [PubMed]

10. Kazwala, R.R.; Daborn, C.J.; Sharp, J.M.; Kambarage, D.M.; Jiwa, S.F.; Mbembati, N.A. Isolation of Mycobacterium bovis from human cases of cervical adenitis in Tanzania: A cause for concern? Int. J. Tuberc. Lung Dis. 2001, 5, 87-91. [PubMed]

11. Oloya, J.; Opuda-Asibo, J.; Kazwala, R.; Demelash, A.B.; Skjerve, E.; Lund, A.; Djonne, B. Mycobacteria causing human cervical lymphadenitis in pastoral communities in the Karamoja region of Uganda. Epidemiol. Infect. 2008, 136, 636-643. [CrossRef] [PubMed]

12. Byarugaba, F.; Etter, E.M.C.; Godreuil, S.; Grimaud, P. Grimaud, P. Pulmonary tuberculosis and Mycobacterium bovis, Uganda. Emerg. Infect. Dis. 2009, 15, 124-125. [CrossRef]

13. Malama, S.; Muma, J.B.; Olea-Popelka, F.; Mbulo, G. Isolation of Mycobacterium bovis from Human Sputum in Zambia: Public Infectious Diseases \& Therapy Isolation of Mycobacterium bovis from Human Sputum in Zambia: Public Health and Diagnostic Significance. Infect. Dis. Ther. 2013, 1, 1-4.

14. Ayele, W.Y.; Neill, S.D.; Zinsstag, J.; Weiss, M.G.; Pavlik, I. Bovine tuberculosis: An old disease but a new threat to Africa. Int. J. Tuberc. Lung Dis. 2004, 8, 924-937. [PubMed]

15. Etter, E.; Donado, P.; Jori, F.; Caron, A.; Goutard, F.L.; Roger, F. Risk Analysis and Bovine Tuberculosis, a Re-emerging Zoonosis. Ann. N. Y. Acad. Sci. 2006, 1081, 61-73. [CrossRef] [PubMed]

16. Romha, G.; Gebre, G.; Ameni, G. Assessment of Bovine Tuberculosis and Its Risk Factors in Cattle and Humans, Assessment of bovine tuberculosis and its risk factors in cattle and humans, at and around Dilla town, southern Ethiopia. Anim. Vet. Sci. 2014, 2, 94-100. [CrossRef]

17. Shitaye, J.E.; Tsegaye, W.; Pavlik, I. Bovine tuberculosis infection in animal and human populations in Ethiopia: A review. Vet. Med. 2007, 52, 317-332. [CrossRef]

18. Sichewo, P.; Etter, E.; Michel, A. Prevalence of bovine tuberculosis in cattle at the wildlife/livestock/human interface in Northern Kwazulu-Natal province, South Africa. In Proceedings of the 9th Veterinary, Paraveterinary \& Southern African Society for Veterinary Epidemiology and Preventive Medicine (SASVEPM) Congress, Boksburg, South Africa, 24-27 July 2017.

19. Michel, A.; Coetzee, M.; Keet, D.; Mare, L.; Warren, R.; Cooper, D.; Bengis, R.; Kremer, K.; Van Helden, P. Molecular epidemiology of Mycobacterium bovis isolates from free-ranging wildlife in South African game reserves. Veter. Microbiol. 2009, 133, 335-343. [CrossRef] [PubMed]

20. National Institute of Communicable Diseases SA. Microbiologically Confirmed Tuberculosis 2004-15 South Africa; National Institute of Communicable Diseases SA: Sandringham, Johannesburg, South Africa, 2016.

21. Human Sciences Research Council (HSRC). South African National HIV Prevalence, Incidence, Behaviour and Communication Survey, 2017; Human Sciences Research Council: Pretoria, South Africa, 2018.

22. TBFACTS.ORG. TB Statistics for South Africa-National \& Provincial [Internet]. 2018. Available online: https://www.tbfacts.org/tb-statistics-south-africa/ (accessed on 12 March 2019).

23. World Health Organisation. Treatment of Tuberculosis Guidelines; World Health Organisation: Geneva, Switzerland, 2010. 
24. Palmer, M.V.; Waters, W.R. Advances in bovine tuberculosis diagnosis and pathogenesis: What policy makers need to know. Vet. Microbiol. 2006, 112, 181-190. [CrossRef] [PubMed]

25. Neeraja, D.; Veeregowda, B.M.; Rani, M.S.; Rathnamma, D.; Narayanaswamy, H.D.; Venkatesha, M.D.; Leena, G.; Apsana, R.; Somshekhar, S.H.; Saminathan, M.; et al. Identification of Mycobacterium tuberculosis Complex by Culture and Duplex Polymerase Chain Reaction in Bovines. Asian J. Anim. Vet. Adv. 2014, 9 , 506-512.

26. Hardies, R.M.; Watson, J.M. Mycobacterium bovis in England and Wales: Past, present and future. Epidemiol. Infect. 1992, 109, 23-33.

27. De la Rua-Domenech, R. Human Mycobacterium bovis infection in the United Kingdom: Incidence, risks, control measures and review of the zoonotic aspects of bovine tuberculosis. Tuberculosis 2006, 86, 77-109. [CrossRef]

28. Tschopp, R.; Aseffa, A.; Schelling, E.; Berg, S.; Hailu, E.; Gadisa, E.; Zinsstag, J. Bovine tuberculosis at the wildlife-livestock-human interface in Hamer Woreda, South Omo, Southern Ethiopia. PLoS ONE 2010, 5, e12205. [CrossRef]

29. Roy, A.; Eisenhut, M.; Harris, R.J.; Rodrigues, L.C. Effect of BCG vaccination against Mycobacterium tuberculosis infection in children: Systematic review and meta-analysis. Open Access 2014, 4643, 1-11. [CrossRef] [PubMed]

30. Vayr, F.; Martin-Blondel, G.; Savall, F.; Soulat, J.-M.; Deffontaines, G.; Hérin, F. Occupational exposure to human Mycobacterium bovis infection: A systematic review. PLoS Negl. Trop. Dis. 2018, 12, e0006208. [CrossRef] [PubMed]

31. Debi, U.; Ravisankar, V.; Prasad, K.K.; Sinha, S.K.; Sharma, A.K. Abdominal tuberculosis of the gastrointestinal tract: Revisited. World J. Gastroenterol. 2014, 20, 14831-14840. [CrossRef] [PubMed]

32. Sharma, S.K.; Kohli, M.; Yadav, R.N.; Chaubey, J.; Bhasin, D.; Sreenivas, V.; Sharma, R.; Singh, B.K. Evaluating the Diagnostic Accuracy of Xpert MTB/RIF Assay in Pulmonary Tuberculosis. PLoS ONE 2015, 10, e0141011. [CrossRef] [PubMed]

33. Datta, S.; Shah, L.; Gilman, R.H.; Evans, A.C. Comparison of sputum collection methods for tuberculosis diagnosis: A systematic review and pairwise and network meta-analysis. Lancet Glob. Heal. 2017, 5, e760-e771. [CrossRef]

34. Katale, B.Z.; Mbugi, E.V.; Kendal, S.; Fyumagwa, R.D.; Kibiki, G.S.; Godfrey-Faussett, P.; Keyyu, J.D.; Van Helden, P.; Matee, M.I. Bovine tuberculosis at the human-livestock-wildlife interface: Is it a public health problem in Tanzania? A review. Onderstepoort J. Vet. Res. 2012, 79, 84-97. [CrossRef]

35. Rocha, A.; Elias, A.R.; Sobral, L.F.; Soares, D.F.; Santos, A.C.; Marsico, A.G.; Hacker, M.A.; Caldas, P.C.; Parente, L.C.; Silva, M.R.; et al. Genotyping did not evidence any contribution of Mycobacterium bovis to human tuberculosis in Brazil. Tuberculosis 2011, 91, 14-21. [CrossRef]

36. Ouassa, T.; Borroni, E.; Loukou, G.Y.; Faye-Kette, H.; Kouakou, J.; Menan, H.; Cirillo, D.M. High Prevalence of Shared International Type 53 among Mycobacterium Tuberculosis Complex Strains in Retreated Patients from Côte d'Ivoir. PLoS ONE 2012, 7, e45363. [CrossRef]

37. Adesokan, H.K.; Jenkins, A.O.; Soolingen, D.; Van Cadmus, S.I.B. Mycobacterium bovis infection in livestock workers in Ibadan, Nigeria: Evidence of occupational exposure. Int. J. Tuberc. Lung Dis. 2012, 16, 1388-1392. [CrossRef]

38. Fetene, T.; Kebede, N.; Alem, G. Tuberculosis Infection in Animal and Human Populations in Three Districts of Western Gojam, Ethiopia. Zoonoses Public Heal. 2011, 58, 47-53. [CrossRef]

39. Michel, A.L.; Geoghegan, C.; Hlokwe, T.; Raseleka, K.; Getz, W.M.; Marcotty, T. Longevity of Mycobacterium bovis in raw and traditional souring milk as a function of storage temperature and dose. PLoS ONE 2015, 10, e0129926. [CrossRef] [PubMed]

40. Mazwi, K.D. Longitudinal Monitoring of Mycobacterium bovis and Non-Tuberculous Mycobacteria in Cow's Milk from a Rural Community. Dissertation's Thesis, Department of Veterinary Tropical Disease, University of Pretoria, Pretoria, South Africa, 2018.

41. Rodwell, T.C.; Moore, M.; Moser, K.S.; Brodine, S.K.; Strathdee, S.A. Tuberculosis from Mycobacterium bovis in Binational Communities, United States. Emerg. Infect. Dis. 2008, 14, 909-916. [CrossRef] [PubMed]

42. Mfinanga, S.G.; Mørkve, O.; Kazwala, R.R.; Cleaveland, S.; Sharp, J.M.; Shirima, G.; Nilsen, R. The role of livestock keeping in tuberculosis trends in Arusha, Tanzania. Int. J. Tuberc. Lung Dis. 2003, 7, 695-704. 
43. Ibrahim, S.; Cadmus, S.I.B.; Umoh, J.U.; Ajogi, I.; Farouk, U.M.; Abubakar, U.B.; Kudi, A.C. Tuberculosis in humans and cattle in Jigawa State, Nigeria: Risk factors analysis. Vet. Med. Int. 2012, 2012, 865924. [CrossRef] [PubMed]

44. Nafarnda, W.D.; Obudu, C.E.; Omeiza, G.K.; Enem, S.I.; Adeiza, M.A. Prevalence of Zoonotic bovine tuberculosis and associated risk factors among cattle herds in North Central Nigeria. Int. J. Curr. Res. Acad. Rev. 2015, 3, 113-119.

45. Mbugi, E.V.; Katale, B.Z.; Siame, K.K.; Keyyu, J.D.; Kendall, S.L.; Dockrell, H.M.; Streicher, E.M.; Michel, A.L.; Rweyemamu, M.M.; Warren, R.M.; et al. Genetic diversity of Mycobacterium tuberculosis isolated from tuberculosis patients in the Serengeti ecosystem in Tanzania. Tuberculosis 2015, 95, 170-178. [CrossRef] [PubMed]

46. Adesokan, H.K.; Akinseye, V.O.; Sulaimon, M.A. Knowledge and practices about zoonotic tuberculosis prevention and associated determinants amongst livestock workers in Nigeria; 2015. PLoS ONE 2018, 13, e0198810. [CrossRef]

47. Warren, R.M.; Van Pittius, N.C.G.; Barnard, M.; Hesseling, A.; Engelke, E.; De Kock, M.; Gutierrez, M.C.; Chege, G.K.; Victor, T.C.; Hoal, E.G.; et al. Differentiation of Mycobacterium tuberculosis complex by PCR amplification of genomic regions of difference. Int. J. Tuberc. Lung Dis. 2006, 10, 818-822.

48. Gcebe, N.; Rutten, V.; Gey van Pittius, N.C.; Michel, A. Prevalence and distribution of non-tuberculous mycobacteria (NTM) in cattle, African buffaloes (Syncerus caffer) and their environments in South Africa. Transbound. Emerg. Dis. 2013, 60 (Suppl. 1), 74-84. [CrossRef]

49. Hlokwe, T.M.; van Helden, P.; Michel, A. Evaluation of the Discriminatory Power of Variable Number of Tandem Repeat Typing of Mycobacterium bovis Isolates from Southern Africa. Transbound. Emerg. Dis. 2013, 60, 111-120. [CrossRef]

50. Venables, W.N.; Ripley, B.D. Modern Applied Statistics with S; Statistics and Computing; Springer: New York, NY, USA, 2002.

(C) 2019 by the authors. Licensee MDPI, Basel, Switzerland. This article is an open access article distributed under the terms and conditions of the Creative Commons Attribution (CC BY) license (http://creativecommons.org/licenses/by/4.0/). 